\title{
Monetary Materialities of Peer-Produced Knowledge: The Case of Wikipedia and Its Tensions with Paid Labour
}

\author{
Arwid Lund* and Juhana Venäläinen** \\ *Uppsala University, Uppsala, Sweden, arwid.lund@abm.uu.se \\ **University of Eastern Finland, Joensuu, Finland, juhana.venalainen@uef.fi
}

\begin{abstract}
This article contributes to the debate on the possibilities and limits of expanding the sphere of peer production within and beyond capitalism. As a case in point, it discusses the explicit and tacit monetary dependencies of Wikipedia, which are not only ascribable to the need to sustain the technological structures that render the collaboration possible, but also about the money-mediated sustenance of the peer producers themselves. In Wikipedia, the "bright line" principle for avoiding conflicts of interest has been that no one should be paid for directly editing an article. By examining the aftermath of the Wiki-PR scandal, where a consulting firm was allegedly involved in helping more than 12,000 clients to edit Wikipedia articles until 2014, the goal of the analysis is to shed light on the paradoxical situation where the institution for supporting the peer production (Wikimedia Foundation) found itself taking a more strict perspective vis-à-vis commercial alliances than the unpaid community editors.
\end{abstract}

Keywords: Wikipedia, Wiki-PR, Materialities, Peer Production, Commons

\section{Introduction}

Peer production has often been portrayed as a potential complement or a radical alternative to capitalism (e.g. Moore 2011; Rigi 2013). As an early and prominent figure in the debate, Yochai Benkler (2002; 2006; 2011) depicted the regime of commons-based peer production as a revolutionary social form that will eventually transform the ways of organizing production in the contemporary economy. He argues that peer production has "systemic advantages" over markets and firms in allowing "larger groups of individuals to scour larger groups of resources in search of materials, projects, collaborations, and combinations than is possible for firms or individuals who function in markets" (Benkler 2002, 381, 376-377). Still, Benkler never moves out of the capitalist paradigm, but rather sees capitalism as being vitalized by peer production, not superseded by something new and different.

One of the focal lines of inquiry with regard to the possibilities of expanding the peerproduction regime towards the boundaries of capitalism has been the question of the conditions of its social and material reproduction, and especially the prospect of taking a step from the digital co-production of information towards the distributed production of tangible goods (Siefkes 2008; 2012; Davey 2010; Troxler 2010; Kostakis 2013; Kostakis and Papachristou and 2014; Kostakis, Niaros and Giotitsas 2014). Indeed, for a regime of peer production to be sustainable and generalizable, it has to account not only for the maintaining of the sociocultural practices of benevolent sharing, but also for the material, technological and biophysical resources necessarily interlinked to the chains of symbolic production. In addition, to construct a regime of commons-based production beyond or regardless of capitalist relations of production, there has to be a framework that provides safeguards against the pitfalls of coopting the peer production processes back to the circulation of commodities and to the accumulation of capital (Federici and Caffentzis 2013).

In this article, we seek to contribute to the unveiling of the materialities of commons-based peer production by examining the lines of conflict in the economic relations of Wikipedia. In specific, we will interrogate the disputed boundary lines in the uses of paid labour in producing and reproducing Wikipedia as a collection of open-access knowledge. Some of the paid 
positions related to Wikipedia, such as the "Wikipedian in residence" scheme tailored for museums, libraries, and other non-profits, are almost universally accepted within the editing community, while others, such as working for a public relations agency, are fiercely contested. In our understanding, these tensions reveal and highlight some of the highly important but mostly unspoken political positions within the project. The disputed cases of paid editing and paid advocacy can be seen to pose risks to the encyclopaedic ideals (Osman 2014) but also, perhaps more unexpectedly, to introduce new emancipatory advantages (Lund 2015a).

In the analysis, we will introduce the concept of monetary materialities by which we refer to the flows of finance that are indispensable for sustaining and expanding Wikipedia as a viable and valuable project. In the widest sense, these materialities include, first of all, the operating costs of the technological infrastructures intermeshed with the informational content of the encyclopaedia, and secondly, the monetary income required by its voluntary contributors to maintain their livelihoods. It is our conviction that these elementary preconditions of social reproduction - as well as the plethora of planetary assets such as metals and oil backing the digital infosphere - have too often been overlooked in the discussions on the commons and peer production (for notable exceptions, see Bauwens and lacomella 2012; Federici 2012).

From the point of view of Wikipedia's neutrality ideals, the monetary flows for funding its material necessities should be kept far away from the symbolic flows of information that constitute the sought-for content of the encyclopaedia (Osman 2014, esp. 597). Still, Wikipedia has seen plenty of events that have disturbed the "bright line" that calls for excluding paid advocates. As Wikipedia has reached a critical mass and proved capable of providing a broad range of quality information, it has also become an attractive platform for commercial actors to promote their interests (Lund 2015b).

As a starting point to the discussion, we will reflect the case of Wiki-PR, a consulting firm allegedly involved in helping more than 12,000 companies to edit Wikipedia articles for their commercial interests. Accused of violating the community rules, Wiki-PR, including all of its employees, owners, and contractors, was banned from Wikipedia in early 2014. The scandal was accompanied by policy proposals for and against regulated paid advocacy, thus opening up a space for the discussion about the confluence of commercial and non-commercial motivations. As the community process did not result in a consensus for ruling out paid advocacy, the governing body, Wikimedia Foundation, intervened by introducing an amendment to the Terms of Use that apply to all of its projects, effectively prohibiting non-disclosed paid editing.

Within this context, we ask: how do Wikipedians perceive and negotiate the alliances of commons-based peer production with the capitalist economy in terms of reproducing the sustenance of their own lives and the informational use value of the project? While our implications are not confined to Wikipedia as a particular case, we consider it as an instructive example in the debates on the commons as a breeding ground for radical politics (e.g. Hardt and Negri 2009; Mattei 2011; De Angelis 2012; Dardot and Laval 2014; Caffentzis and Federici 2014).

Based on an analysis of The Signpost, a community newspaper of English Wikipedia, and the internal discussions about the changes in policies and Wikimedia Foundation's Terms of Use, we will highlight three aspects of the Wiki-PR scandal. First, we will examine the different perspectives from which the paid advocacy was represented as the events unfolded. Second, we will show how in the course of the consequential votes about the proposed policies against paid advocacy the response from the editing community was relatively more liberal than the one from Wikimedia Foundation. Third, we will discuss and interpret the politics of the proposed changes in the terms of use of the Wikimedia projects by the foundation that was later accepted by the community with a few amendments. To support the analysis, we will begin by discussing the socio-technical materialities of peer production in general, and then the monetary materialities of Wikipedia in particular. 


\section{Socio-Technical Materialities of Peer Production}

The concept of peer-to-peer technology has been used as an umbrella term to describe everything from YouTube, operating on a fully commercial and closed platform, to open networks using the BitTorrent protocol for co-operation. For example, Pouwelse et al. $(2008,703)$ understand the paradigm of peer-to-peer broadly as an "enabling mechanism for human interaction and cooperation on an unbounded scale that lacks central points of authority and is helped by mutual donations of computer resources".

Wikipedia, with its 128 million articles in more than 280 language versions, is unarguably the largest existing collection of organized digital knowledge created by voluntary contributors and thus, a paragon of networked mass collaboration. In addition to being a huge "pool of immaterial labour" (Corsani, Lazzarato and Negri 1996) and a "massively multi-user knowledge management exercise" (Bruns 2011, 134), it is supported by a dense mesh of material structures: data centres, telecommunications cables, cooling systems, and all of electrical electronic energy required to service about 7,700 page requests per second (in April 2015) (Wikimedia Stats 2015).

When discussing the socio-technical materialities ${ }^{1}$ of Wikipedia as a platform of peer production, it is worth noting that while the pool of knowledge is created and maintained in a largely self-organized social process, the technological resources are, for the most part, owned and managed by a central governing body, the Wikimedia Foundation. These resources include, among others, the data centres in Ashburn (Virginia), Amsterdam, San Francisco, and Carrolton (Texas), providing the calculation power, storage capacity, and the high-speed Internet connections for serving the close to 500 million users of Wikimedia projects ${ }^{2}$. (Meta-Wiki contributors 2015b; Wikimedia Stats 2015; Paumier 2013; Verge 2013.)

Wikipedia is run mostly on open-source software. In addition to GPLv2-licensed MediaWiki, Wikimedia Foundation's in-house solution for content management, Wikipedia's architecture includes an array of open-source software from Ubuntu (the operating system used in the servers) to PowerDNS (for distributing the page requests depending on the location of the client), Linux Virtual Server (for load balancing), and MariaDB (for database management) (Meta-Wiki contributors 2015b). Thus, the technological backbone of Wikipedia is based on a hybrid economy: the centralized, money-mediated and proprietary hardware layer, and the decentralized, commons-based open-source software layer.

Analytically, it is important not to conflate the socio-cultural practices of sharing (the mutual contributions of time, knowledge, and other resources at hand) with the technological structures that mediate the process. Technological factors of peer production do not determine the success or failure of cooperation in a peer-to-peer scheme, but they might still have some effects on the formal and informal codes of conduct within a commons. There is a difference between the more centralized platforms running proprietary software and holding a majority of the rights in private hands, and the more decentralized platforms and architectures, such as Wikipedia's, that reserve (and can reserve) more rights for the rank and file of the participating commoners. Decentralized platforms that distribute the rights more horizontally within the community often utilize copyleft licensing in tandem with the formal and informal codes of conduct that encourage and reward altruistic modes of behaviour.

Within the peer-to-peer debates, Michel Bauwens (2009) has stressed the relation between the social and technological aspects of peer production. He sees peer production as a relational dynamic that could mediate relations between machines but more importantly with

\footnotetext{
${ }^{1}$ As Leonardi (2012) remarks, there has been a broad overlap in the uses of terms such as "materiality", "sociomateriality" and "socio-technical systems". By socio-technical materialities, we refer here to the mutually constitutive and mutually nourishing interlinkage between the socio-cultural practices and the technological layers (hardware and software) of cooperation. In the case of Wikipedia, this implies that the tools of cooperation are informed by the concrete needs arising from the process of commoning (Linebaugh 2008; Esteva 2014), but also that the modes of behaviour and codes of conduct are influenced by the technological solutions (Benkler and Nissenbaum 2006).

${ }^{2}$ These include, in addition to Wikipedia, a free dictionary (Wiktionary), two full-text collections (Wikibooks, Wikisource), a multimedia repository (Wikimedia Commons), a data repository (Wikidata), and several others. (Wikipedia contributors 2015b; Wikimedia Foundation 2015.)
} 
relations between human beings: the peers. It is in this context that he makes a distinction between peer production and Web 2.0 services. When capitalist actors like Flickr (the quasicommons, as Brown 2012 puts it) and YouTube certainly make participation possible and encourage it, they mainly invite participants to be involved as individuals. There is no creation 'in common', except for the common sphere for the exchange of activities. He calls this a sharing mechanism, whereas peer production is instead grounded in a commons mechanism where production occurs in a form of voluntary exchange between equals in horizontal networks within the commons (Bauwens 2009, 125-127; Gye 2007a; Gye 2007b).

Over the course of the modern history of information and communications technology, a less challenged assumption behind its political promise has been that, in the long run, the cost of reproducing information will approach zero, as Moore's law will make technology exponentially more affordable (see Negroponte 1988). The technological layers of production, while still necessary, have been understood to become a mere backdrop to the more valuable operations in the value chain-it is, for the production of the informational or "cognitive" commodity (Moulier Boutang 2011, 50-56; cf. Starosta 2012). This prospect, for its part, has led prominent network society theorists such as Jeremy Rifkin (2014) to estimate that the possibilities for the costless sharing of information would bring us to a profound socioeconomic transformation: in effect, it would gradually lead to capitalism becoming inherently 'communist', as there is no legitimate reason for denying access to the common prosperity (cf. Virno 2004, 110; Beverungen, Murtola and Schwartz 2013).

To push the point slightly further, we could argue that the imageries of digital production have been driven by an unquestioned credo of affluence. This has been particularly the case in the discourses of free and open-source software, peer-to-peer production, and the Creative Commons. In contrast to the scarce world of natural commons-tillable land, drillable oil, potable water - which from day one of environmental awakening have been identified as vulnerable to a tragically uncoordinated overexploitation (Hardin 1968), the theorists of digital commons (e.g. Boyle 1997; Lessig 2000; Litman 2001) broke ground for the notion of the "infosphere" of Internet as a realm of abundance, where the tragedy of the commons would be overturned by a sharing economy for the benefit of all. Once the artificial barriers of sharing (such as overregulated intellectual property rights) have been dismantled, a veritable "comedy of commons" (Rose 1986) could take place and the creation of prosperity could derive from a "social commerce of the human spirit" (Bollier 2001). Of course, the dichotomy between scarce nature and "non-scarce" digital information is far from obvious, as the prerequisites for actually producing and consuming the information-mainly, time-are practically limited.

While the extent of the social and cultural implications of the ICT revolution can hardly be questioned, overly optimistic views on peer production might actually hinder the critical potential of the concept itself. Media philosopher Matteo Pasquinelli $(2008,72-73)$ has described this misconception as a "digitalist utopia", where production is portrayed as a purely symbolic exchange between self-standing individuals, largely independent of the physical, biological, financial or socio-cultural conditions of sustaining the production. The "ideology of digitalism" promotes an understanding of energy-free production of data which is "virtually free from any exploitation, tending naturally towards a democratic equilibrium and natural cooperation" (ibid, 72), also neglecting the question of the environmental sustainability of distributed production (cf. Kohtala 2014; Kohtala and Hyysalo 2015).

In contrast to the digitalist abstraction, we conceive the social processes of digital production as being inherently and inescapably material, but vice versa, we see the involved materialities as always and already socio-culturally shaped: they do not exist "behind" social action and cultural norms as infrastructures nor "above" them as superstructures, but rather at the very same ontological level (cf. DeLanda 2002; 2006, 4-5).

Certainly, peer production as a socio-cultural practice is not reducible to its material constituents. It is a novel form of co-production, but still its potential in reshaping or partially transcending capitalism cannot be accounted for without thoroughly examining its dependencies on the money-mediated economy and the Earth's planetary boundaries. Without scrutinizing the material conditions of reproduction of the digitally mediated production processes, 
there is a risk of contributing to a romanticized view of peer production, a position which would serve neither the purpose of analytical clarity nor the efforts for building ecologically and socially sustainable futures.

The materialities of the digitally networked production usually manifest themselves only in the event of a malfunction, external disruption, or social or political conflict. This is not only an accidental feature of the digital infosphere, but also an intended purpose of digital businesses that stress the importance of a seamless user experience at the cost of transparency. The purported goal of the service providers is, as Google CEO Larry Page phrases it in Google's 2011 Annual Report, that "technology should do the hard work" while users can do what makes them happy: "living and loving, not messing with annoying computers!" (Google 2011, ii; cf. Lovink 2009). For another example, Apple has undoubtedly been one of the forerunners in advocating an intuitive approach to computing and mobile devices. In the 2011 WWDC fair, Steve Jobs mentioned that for ten years already, they had been working "to get rid of the file system so the user doesn't have to learn about it" (WWDC 2011). In terms of epistemic self-governance, Apple's ambition is rather far-reaching in trying to convince users that they should not bother where their data are logically or materially situated-or, by extension, how it is used, by whom, and for which purpose.

In case of Wikipedia, the public expectations for transparency are evidently higher than in the corporate Internet settings. Wikipedia can be conceived as an ambitious experiment of participatory democracy, armed for producing common good for all. Even while it proclaims itself as a politically neutral project, it is starkly ideological in a sense that it suggests very high standards of democratic participation and access to knowledge. Obviously, the reality of Wikipedia's production process might not meet all of the ideals; in contrast, there has been a constant worry about a systemic bias for educated Western white male contributors (Brake $2014,599)$. There are certainly a number of "digital divides" behind the façade of equality. Also, as concluded by José Felipe Ortega in his quantitative analysis of ten biggest language versions of Wikipedia, the division of labour within the community is rather skewed, and there is a "heavy dependence" of Wikipedia on the work of a small core of very active editors. In Ortega's data, less than $10 \%$ of authors made more than $90 \%$ of the contributions of content. (Ortega 2009, 106-107.)

\section{Wikipedia's Monetary Materialities}

At the surface level, the operational logic of Wikipedia seems markedly detached from commercial dependencies and openly unsympathetic towards them: after all, Wikipedia is an "encyclopaedia that anyone can edit"-a free service hosted by a non-profit foundation. It is based upon encyclopaedic ideals not so dissimilar to the ones of scientific research: communalism, universalism, disinterestedness and organized scepticism (Merton 1973). However, even Wikipedia cannot completely rule out the realm of the prevailing monetary economy. While the digitalized knowledge itself might be free and open, the material structures of its production and reproduction are still largely governed by the ordinary laws of the market.

In a simplified view, Wikipedia is sustained by two major income streams: 1) the donations of money (in US dollars) for the Wikimedia Foundation (WMF) and 2) the unpaid work of the contributors for providing the content of Wikipedia. The donations are channelled by WMF to wages, grants to their local subsidiaries, and other expenses such as infrastructure costs, while the unpaid work is accumulated directly in the informational content of the encyclopaedia (Figure 1). In the following paragraphs, we will discuss the two tiers of Wikipedia's gift economy: first, the donations of money, and second, the donations of work time. 


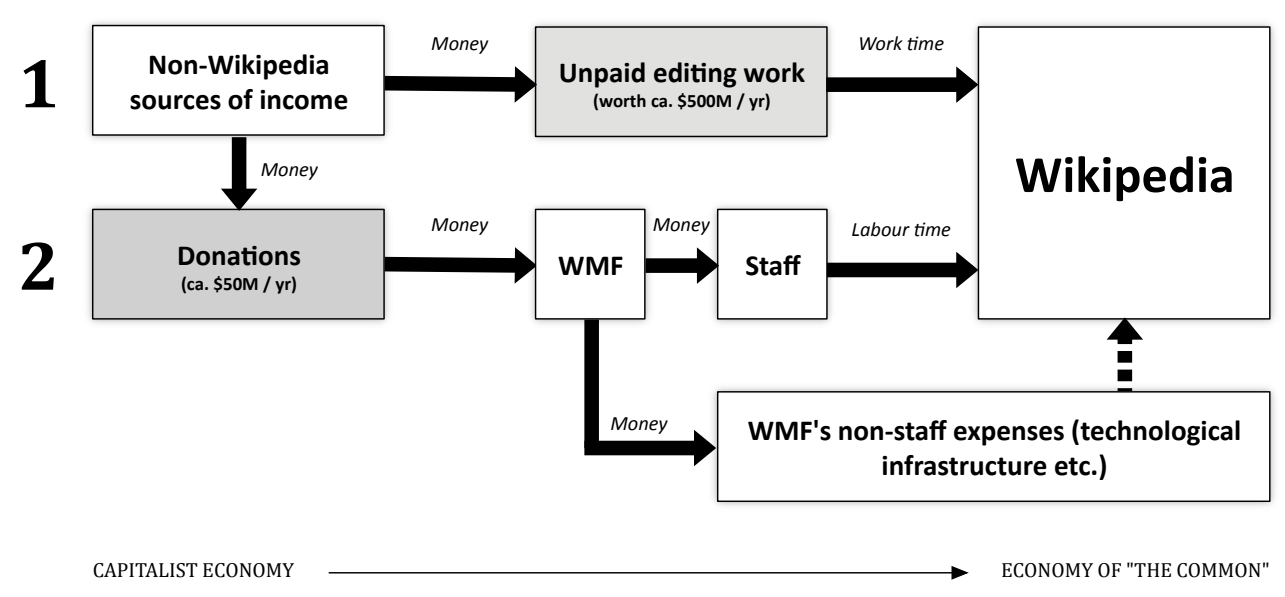

Figure 1: Wikipedia's two-tier gift economy: donations of money and donations of time.

\subsection{Donations in Money to Cover WMF's Expenditure}

Wikimedia Foundation (WMF), the governing body of the peer-produced encyclopaedia, has annual expenses of about $\$ 50$ million per year $\left(2013-2014^{3}\right)$. Salaries and wages constitute the biggest category of expenditure, just slightly under \$20 million in 2013-2014. Since the establishing of the foundation in 2003 , staff costs have been rising rapidly, whereas the cost of Internet hosting and other non-staff expenses have remained relatively modest. The growth of salaries and wages correlates with the impressive success of the latest fundraising campaigns - the one in 2013-2014 yielded over \$51 million, doubling the total amount of donations in the span of two years (Figure 2).

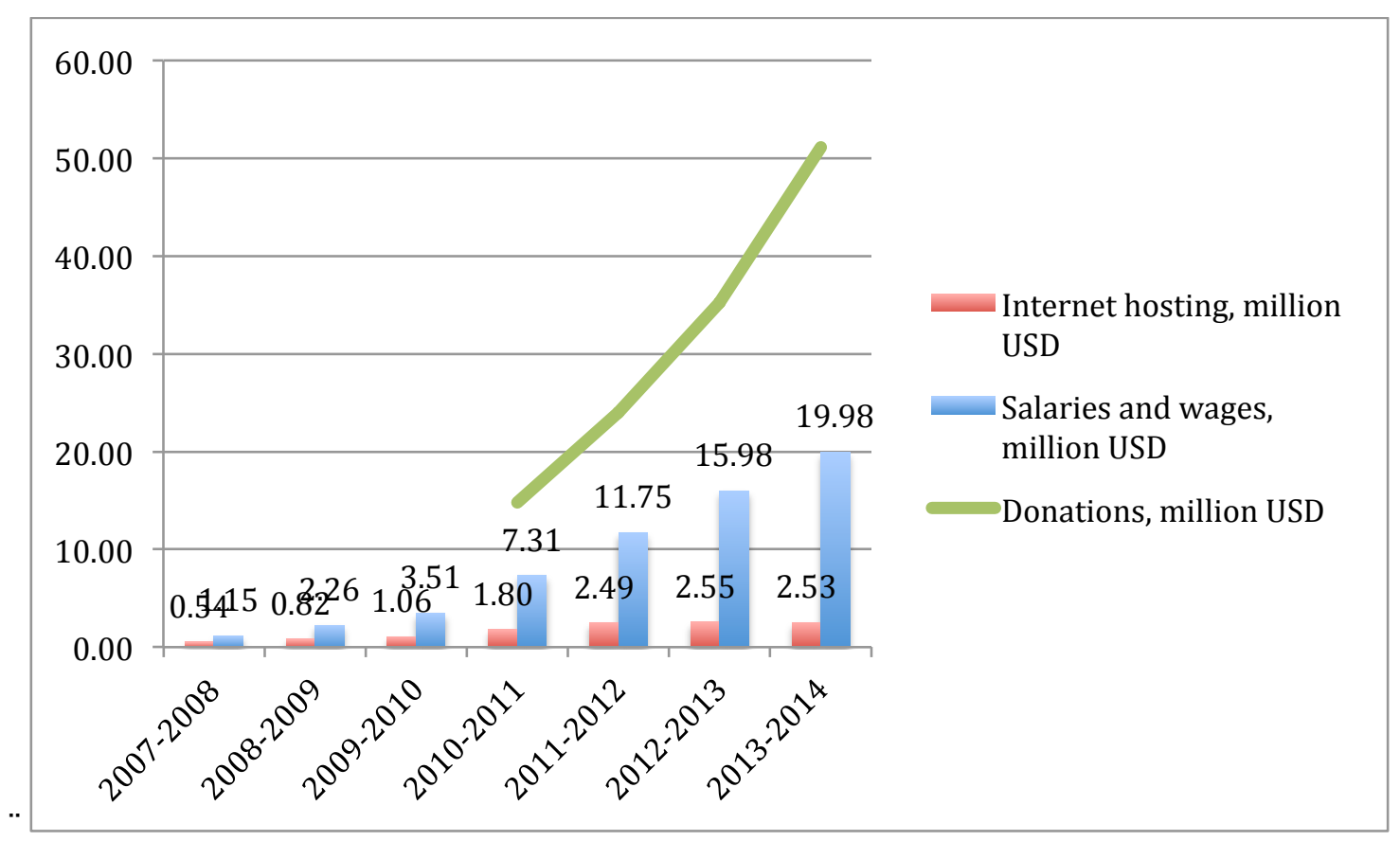

Figure 2: The growth of major expenses of the Wikimedia Foundation in 2007-2014.

For 2014-2015, WMF planned to hire 49 additional staff members, adding up to 240 employees (WMF Annual Plan 2014-2015, 9-10). The rapid increase in WMF's paid staff has

\footnotetext{
${ }^{3}$ The fiscal year of WMF lasts from 1 July to 30 June, so e.g. 2013-2014 refers to a single year.
} 
given rise to criticism concerning whether the foundation would even need the donations that it is asking for (Orlowski 2012). The growth of the paid staff might increase the tension in relation with the contributors working without compensation.

WMF's expenses are financed almost exclusively by donations from individuals, commercial firms, non-profits and national states and with some minor income streams from the sales of updates and feeds to search engines. The donation base of WMF is relatively wide and has been growing: in the financial year of 2013-2014, 2.5 million people donated an average of $\$ 15 .{ }^{4}$ As only two in a thousand persons donated over $\$ 1,000$, it can be seen that the bulk of financing of Wikimedia Foundation comes from the very heterogeneous masses. Thus, it would seem for Wikipedia to be in a relatively strong position to block any potential attempts to influence the substance of the encyclopaedia through bribery. Supporting these observations, the earlier study of Swedish Wikipedia (Lund 2015a) shows that the necessary self-confidence of the editing community to build alliances with capital for the benefit of the project depends very much on the plentitude of the donations, as well as the use of the core content principle of Neutral Point of View (NPOV) to curb capital's boundless desire to make profit in whatever manner as possible.

\subsection{Donations of Time by the Unpaid Editors}

The monetary flows that allow for the continuity of Wikipedia's technological infrastructure and its paid staff are only one side of the coin, the other being the unpaid work providing the informational content that makes Wikipedia valuable to its users and potentially also to the commercial actors in its margins. In 2012-13, volunteer contributors made over 160 million edits, added almost 5 million articles and uploaded more than 4 million new images, audio files and video files (WMF 2014).

While the amount of donations is revealed in WMF's financial statements, the value of the unpaid labour is obviously more difficult to estimate, but there have been a few attempts to do exactly that (Juhel 2011; Geiger and Halfaker 2013; see Band and Gerafi 2013, 4).

Vincent Juhel used several methods to derive the amount of working hours and/or their economic value. For example, he calculated that an annual increase of 70 million characters in the French Wikipedia would equal $€ 32.3$ million if written by freelance journalists at the standard rate of 57.74 euros per 1500 characters. Assuming a monthly salary of $€ 3,000$, this adds up to about 900 full-time jobs for the French Wikipedia alone (Ibid. 16). A comparable figure is reached by multiplying the number of annual edits by an estimated average time of 10 minutes per edit (Ibid. 15). If applied for all language versions, this formula yields an expenditure of about $€ 431$ million ( $\$ 485$ million), i.e. 12,000 full-time jobs. ${ }^{5}$ Juhel's estimates are supported by findings of Geiger and Halfaker (2013). Analysing the English Wikipedia's log files, they came up with a figure of 425,000 labour-hours per month in 2012, which would extrapolate to about $€ 437$ ( $\$ 492$ million) per year, using the same assumptions as above. ${ }^{6}$ If the scale of these estimates is approximately correct, it seems that the economic value of the unpaid work (if it were to be purchased from the market) is almost ten times the sum of Wikimedia Foundation's annual income in money.

One of the dismissed or underemphasized aspects of the digitally networked peer production has been the cost of reproducing the labour power, or in the case of Wikipedia, the reproduction of the voluntary workers or Wikipedians. While the majority of Wikipedians still earn their living outside of the project in entirely capitalist relations of production that have little to do with the "commonist" gift economy (Schantz 2013, 75-82) of Wikipedia, there are an increasing number of possibilities of getting paid either within the project, or by using the

\footnotetext{
${ }^{4}$ This figure, which is reported in WMF's Annual Report, is the average sum of donations under $\$ 10,000$. If the larger donations were included, the average would be $\$ 19.14$, as indicated in the actual fundraising report. (See Meta-Wiki Contributors 2015a.)

${ }^{5}$ This estimate is our calculation based on the "Wikipedia Edits per Month" statistics (Wikimedia Stats 2015), from May 2014 to April 2015. The assumptions are: 10 minutes per edit; 140 editing hours per month; a salary of $€ 3,000$ per month, including ancillary costs.

${ }^{6}$ Assuming that the share of the English Wikipedia in total edits is approximately 25\% (as it was in April 2015, according to Wikimedia Stats 2015).
} 
skills developed within the editing community for activities outside or on the fringe of it. For example, the Swedish Wikipedia has developed a project together with the Swedish National Heritage Board (Riksantikvarieämbetet). The Board's staff will be educated in how to edit Wikipedia by a Wikipedian in Residence. Subject specialists, wage labourers of the Board, are thus getting paid in order to be educated about how to contribute to Wikipedia, and their instructor, also paid by the Board, has been selected among the peers in the Wikipedian community.

\section{Wiki-PR and the Disgrace of Paid Editing}

Ganaele Langlois and Greg Elmer $(2009,775)$ have argued that Wikipedia functions as an arena for political campaigning and for implementing companies' PR strategies (Langlois and Elmer 2009, 775). Even Wikipedians themselves have pointed out that the success of the site under the new millennium's first decade has created a constant problem to keep away from all planted ads and junk in the form of sales brochures (Lih 2009, 226).

A way of influencing a company's presence in Wikipedia, then, is to hire a PR consulting firm. An article published in Lawyers Weekly in 2009 gives us an example of how business people try to understand how Wikipedia functions. At the moment, the encyclopaedia has relatively few articles on small and medium-sized companies. As a result of the ban on ads in Wikipedia and the required objective way of editing, the journal addresses the "problem" with "marketing guru Larry Bodine" to get a picture of how companies could contribute in a correct way. The advice given in the article is that "small firm lawyers" should engage someone to write about the company without advertising. They should keep the text short and back it with a historical section and external sources. The guru also stresses the importance of checking the article continuously as well as being rather defensive in attitude (Rebello 2009,).

Kaplan and Haenlein point out that that if someone today googles a company name, the Wikipedia article will typically be among the top results. This could be problematic for the companies that historically have grown accustomed to being in control of the information about them. The authors give ten pieces of advice with regard to social media, and one of them is that you should not lie when you have to do with Wikipedia. As an example, they mention an owner of an aqua amusement park that tried to improve on the park's article with the help of a PR firm and totally failed. (Kaplan and Haenlein 2010,60,62,67.)

How commercial interests and their intervention in the project affect the participation in the project has, to our knowledge, not been widely addressed in research, except for the Spanish fork that stands out in this context. The resulting competition between two different encyclopaedias hampered the development of the Spanish Wikipedia for several years (Guldbrandsson 2008, 146; Lih 2009, 9,137).

However, the case of Wiki-PR and the consequential policy proposals have been previously studied by Kim Osman (2014), who concluded that the commonplace image of Wikipedia as an example of the potential of Internet to support open, free and non-commercial cooperation, is often confused with how reality looks like within its peer production. We agree with Osman that the romanticized imagery of digitalism is a theoretical dead end, but in contrast to his critique's assumptions, we contend that it was not better before. In Wikipedia, paid editing has been critically discussed for many years, and it also has to be noted that Wikipedia did not start out as a non-commercial project, but rather has become less commercial in some respects since the beginning.

\subsection{The Unfolding of the Wiki-PR Scandal in The Signpost}

In August 2012, a Wikipedia user, Doc Tree, was editing an article on the encryption company CyberSafe in August 2012. On the surface, the article seemed to meet Wikipedia's guideline of notability, but when looking into the citations, none of the references dealt with the company. When the article was suggested for deletion, numerous people showed up to defend it. The editing histories of these users were either non-existent or related to the articles about small firms. These people had been hired by a firm called Wiki-PR, which in turn was a subcontractor of thousands of businesses that wanted to influence and improve their pres- 
ence in Wikipedia (Owens 2013). The story was followed up by the UK-based Vice magazine that portrayed Wiki-PR as a multi-million-dollar business, having broken several policies and guidelines on the English Wikipedia as well as editing and maintaining thousands of articles (The ed17 and Jayen466 2013).

One of the companies involved, Priceline.com, told Vice that they were using Wiki-PR to get a presence in the encyclopaedia for all of their brands. The manner of editing was unusual. The initial draft was created on a user subpage by a Wiki-PR employee and then moved to the article space the next day, thus bypassing "the gatekeeping new page patrol" (The ed17 and Jayen466 2013).

All of this led Sue Gardner, then executive director of Wikimedia Foundation, to issue a press statement that was reprinted in full in English Wikipedia's community newspaper, The Signpost. In the statement, she declared that "[e]diting-for-pay has been a divisive topic inside Wikipedia for many years, particularly when the edits to articles are promotional in nature". At the same time as she stressed that paid advocacy editing was "extremely problematic", while singling out the editing of a university professor in his/her area of expertise as unproblematic. The statement claims that, "editing by using sockpuppets ${ }^{7}$ or misrepresenting your affiliation with a company is against Wikipedia policy and is prohibited by our Terms of Use". According to the argument, the companies engaging in self-promotion were being highly criticized by the general public as not in line with "Wikipedia's educational mission" (2013).

Jordan French, the Wiki-PR CEO, issued his own press statement claiming the company was counselling its clients "on how to adhere to Wikipedia's rules". More importantly he stressed: "We do paid editing and not paid advocacy. Our primary goal is to improve Wikipedia. We're part of the fabric of Wikipedia - an integral part - and useful where volunteers don't want to or cannot put in the time to understand a subject". He ends the statement with the claim that there is "a rather silent majority on Wikipedia that supports paid editing" (Jordan French ref. in Go Phightins! et al. 2013).

We claim that an interesting debate starts here that could be interpreted in rather the opposite way compared with Osman's analysis. We will focus on one specific phase of events in our analysis: the subsequent successful amendment in the Terms of Use as a result of the Wiki-PR scandal.

Leading up to the change in the Terms of Use of all Wikimedia projects, Wiki-PR received a community ban and a cease-and-desist letter sent by the Wikimedia Foundation. The ban of Wiki-PR was voted on and enacted by volunteer Wikipedians because the company had proven unable to adhere to basic community standards, and to be unbanned Wiki-PR had to comply to three directives: divulge a list of all past "sock and meatpuppet accounts that they have used", divulge all articles they edited for financial benefit, and pledge to edit "only under transparent, disclosed accounts" and adhere to content policies (The ed17 and Tony1 2013).

\subsection{Failed Policy Proposals}

Following the revelation of the Wiki-PR scandal in November 2013, there were three active policy proposals for regulating paid editing and/or paid advocacy in the English Wikipedia: "No paid advocacy", "Paid editing policy proposal", and "Conflict of interest limit". The oldest of these three, No paid advocacy, had already been drafted in late 2011, reflecting the strong opinions against the use of paid labour as expressed by the Wikipedia co-founder and "constitutional monarch" Jimmy Wales. ${ }^{8}$ In the opening discussion on the talk page, there is a dispute as to whether Wales had the authority to mandate such policy merely by taking it into practice, which would leave the community the role of merely explicating the norms that de facto were already in place.

\footnotetext{
${ }^{7}$ The use of multiple Wikipedia user accounts for an improper purpose is known as sock puppetry and the different false user accounts as sock puppets. When a Wikipedian try to promote his/her cause by bringing his/her friends to the argument, these friends are called meat puppets.

${ }^{8}$ While Wikipedia has often been portrayed as an experiment of non-hierarchical, commons-based governance, Wales has retained a set of exceptional privileges that allow him to overrule the community decision in the last resort, which has led some to describe him as the "benevolent dictator" of Wikipedia (Meta-Wiki contributors 2013b).
} 
However, the discussion on "No paid advocacy" quickly led to lengthy debates on delineating the subsets of paid editing activities that should or should not be allowed. In specific, there was a lack of consensus on what would constitute "advocacy", how it would be identified, and whether the sort of activities would have been already governed by the established core policies such as "Neutral point of view", "Verifiability", and "Biographies of living persons". In comparison with "No paid advocacy", the "Paid editing policy proposal" was slightly more liberal towards the inclusion of paid editors, and the third proposal, "Conflict of interest limit", fell somewhere between the two.

The majority of the participating editors rejected all three proposals. "No paid advocacy" gathered 229 responses ${ }^{9}, 72 \%$ of which were against introducing the new policy.

In contrast to what was claimed by some of the discussants and also by Jimmy Wales, it became clear that there was no consensus within the editing community-in this case in the English Wikipedia, but probably also more generally-regarding how to react to the practice of paid editing.

Osman (2014) identifies 21 different categories or positions in the discussions vis-à-vis the three proposals regarding prohibition or alternatively restriction of paid editing and paid advocacy within the English community, even though all three failed to be accepted. Ten of these categories opposed the elaboration of a policy against commercially grounded editing, nine gave their support to such a policy, and two were neutral but demanded clarifications on the wording of the policy. Some 300 Wikipedians took part in the discussions, and the proposal No Paid Advocacy attracted more discussing participants (256 of them) than the others. Interestingly, there was only one comment in the debate about the involvement of WMF in the question. The community seems to view this very much as their question (Osman 2014, 601-602).

Nine categories out of 21 being explicitly in favour of a policy against paid advocacy is a rather strong reaction against paid advocacy by companies, considering the benefits of the more and more common use of external actors' wage labour in the editing the Wikipedia, and the long trajectory of awareness of paid editing within the peer production without strong protests being launched against it. Instead of interpreting it as a defeat against the logics of capital, it could be seen as a strong reaction for a need to regulate the editing of external actors. At the same time, we see that there is a limit to the political critique. Institutional involvement from the foundation is generally not favoured, which could be a sign of right-wing libertarianism as well as a left-wing stance.

\subsection{Amendment in the Terms of Use of the Wikimedia Projects}

In February 2014, The Signpost reported that WMF proposed to modify the Terms of Use for all the Wikimedia projects. According to the report, the debate extended to 50 sections on the talk page but showed a majority in support of it. The new Terms of Use were targeted to explicitly ban "undisclosed paid editing". The author contends: "This is the Foundation's first major move against the much wider category of paid editing, rather than advocacy, putting it all in the category of "deceptive activities'" (The ed17 2014a). In the proposal that prohibits misrepresentation of affiliation, impersonation and fraud it is required that users disclose their employer, client and affiliation "with respect to any contribution to any Wikimedia Projects" for which they receive compensation. The disclosure could be made as a statement on the user page, on the talk page of the article, or as a statement in the edit summary (The ed17 2014a).

The changes in the Terms of Use provide a clear answer from the foundation to the argument of Wiki-PR that they did not engage in paid advocacy but only paid editing. The foundation is here acting as a defender of last instance against commercial forces, and they are backed by a majority of involved Wikipedians. This contradicts the earlier result of different views between the community and the foundation, when parts of the community wanted to be able to get paid for their editing, editing that they normally would argue was not paid ad-

\footnotetext{
${ }^{9}$ Although commonly referred to as "votes", these decision-making processes are not strictly bound on a majority decision but on a discussion that "helps identify and build consensus" (Wikipedia contributors 2015a).
} 
vocacy but in line with the guidelines and policies of Wikipedia. A preliminary analysis of that contrast suggests that the wage labourers of Wikimedia Foundation and Jimmy Wales do not have to think of the editing of Wikipedia as a way of earning money, and they can, therefore, function as a defender of last resort, more or less, in conflict with the material interests of the Wikipedians that have the opportunity of earning money from paid editing. We contend that the consensus reached regarding the question of the Terms of Use of the Wikimedia projects could be understood as an agreement reached over this conflict of material monetary interests between the foundation and the community. In the new consensus, Wikipedians who can get paid for their editing can continue with it if they are open about it, otherwise not. The bright line of Wales and the initial hard critique of the foundation, together with the rather strong community reaction against paid advocacy, led to this result, which is an example of the maturing of the project and a regulation of the relation to the capitalist economy that is thought to benefit the project as well as the Wikipedians living in capitalism.

It is possible to explain some of the fervour in the discussions around the change in Terms of Use that focused more on the paid editing than on the actual changes that only required disclosure and adherence to Wikipedia's policies as conflicting views on the social reproduction of Wikipedians in a capitalist society. Some annoyance is expressed by user Smallbones over the writings of the ed17 that is said to focus on what is negative with the changes in Terms of Use. User Coretheapple, who propagates clear disclosures to the readers, instead says that his interest in the question has been growing lately due to the "operatic expressions of fear and loathing that l've seen coming from the paid editing fan club. This indicates to me that there is genuine concern that the community may curb the practice effectively" (The ed17 2014b). This commsent can be seen as a sign of friction within the community - perhaps between those who have a paid job elsewhere and those trying to make a living as Wikipedians. In terms of the total social reproduction of Wikipedia, these positions point to very different perspectives: to the one that implicitly accepts Wikipedians' persistent dependence on paid labour performed outside of the sphere of the commons, thus maintaining a clear boundary and a "bright line" between the domains of work and leisure; and to the one that would not mind to see wage labour more integrated in the commons-based production system.

But the Swedish Wikipedia, for example, welcomes paid editors for much more practical reasons: the wellbeing of the encyclopaedia and its use value. According to The Signpost, a Swedish Wikipedian Anders Wennersten writes that paid editing is only a problem for the privileged English language version. As long as the paid advocacies play by the elementary rules, they are key stakeholders in helping Swedish Wikipedia to improve in value and quality. Also, the Norwegian Wikipedia is reported to contend that a straight ban on paid editors would be "wholly impractical" (The ed17 2014a).

Different Wikimedia projects have different needs. According to The Signpost, Wikimedia Commons is an example of a potential exception to the new rule. The project depends on high-quality photographs submitted by users who often receive compensation for them. The result of the extensive community discussion was the adoption of an opt-out clause that "allows WMF projects to adopt an alternative disclosure policy if there is clear community consensus for it" (The ed17 2014b).

The ed17 concludes: "The wide scope of this amendment will cover a large number of good-faith editors-but it also grants the WMF's legal team a weapon that they will selectively enforce against bad-faith actors, such as the former Wiki-PR" (The ed17 2014b). User Phoebe also makes clear in a comment to the article that you do not have to disclose anything if you are an expert in something or employed within a field: "It's only if you are directly employed to edit about your company, or a product, or what not." (The ed17 2014b)

In any case, the critique against paid editing and advocacy has provoked significant changes, including a regulation of praxis in relation to the capitalist system under the guidance of the Neutral Point of View (NPOV). A distinction is made between the regimes of the market economy and the economy of the common, while at the same time it is accepted that the reproduction of the Wikipedians as Wikipedians (in a capitalist world) is partially paid for by external and even commercial actors. 


\section{Rematerializing the P2P Debate}

Wikipedia's relative financial independence is rendered possible by the relative economic strength of the donation-based funding model of Wikimedia Foundation. The financial model is a strong factor in what Lund (2015a) has called the capitalism of communism. What is important is the plenitude and heterogeneity of the donor base: the donations are many and small, but taken together, they contribute to Wikipedia's economic self-sufficiency, which is not too dependent on the interests of any specific actor. This gives some independence to the project in relation to individual capitals, but of course it indirectly rests on a dependency on capitalism as a system.

The breadth of the community base of mainly voluntary producing amateurs and the popular character of the donations overthrow some commonplace understandings regarding the division of labour and specialization. The notion of Marx that in the communist society no one should have an exclusive occupation but instead realize him/herself within whatever profession interests him/her, seems a bit less unrealistic with Wikipedia in mind. Exactly as when Marx talks of "well-rounded" and "complete individuals" in social association that is universal in character and transforms the productive activity into a self-activity that phases out the regime of private property, Wikipedia makes it possible to do one thing today and another tomorrow: "to hunt in the morning, fish in the afternoon, rear cattle in the evening, and criticise after dinner, just as I have a mind, without ever becoming hunter, fisherman, shepherd or critic" (Marx and Engels 1998, 53, 97). Wikipedia as a project is not dependent on individual persons, and the collaboration takes place in an ad hoc manner in relatively free digital networks (without forgetting that the digital divide and the global differences still play a crucial role) that enables the participants to scale up the production of use values because of the relatively cheap reproduction of digital files.

Sylvain Firer-Blaess and Christian Fuchs have put similar thoughts forward in an article that contends that Wikipedia has communistic potentials "antagonistically entangled into capitalist class relations" (Firer-Blaess and Fuchs 2014, 99). Our article makes a parallel contribution in examining how antagonistic the relation actually is, within which time horizon, and whether synergies and un-holy alliances with capital might also be important for the development of communism. Firer-Blaess and Fuchs are right in saying that Wikipedia with its practices and roots within what they call "info-communism" is introduced in the economic structures through a profit-driven infrastructure and the market for personal computers, through which a well-educated and global working class with enough leisure time and knowledge can make contributions to the real and not only the ideological realization of infocommunism: "The free knowledge production by Wikipedians is a force that is embedded in capitalism, but to a certain degree transcends it at the same time. A new mode of production can develop within an old one" (Ibid). In their view, info-communism seems to mark a transition to a dominating communism pure and simple. This kind of communism is characterized by a level of high-technological productivity that enables a "post-scarcity society" which holds a promise of ending hard and alienated toil and yielding opportunities for creative work for all human beings (Firer-Blaess and Fuchs 2014, 90). In addition to this we just would like to point out the obvious that it was capitalism (or paid and exploited labour) which created the necessary conditions for Wikipedia, with its dependency on educated contributors with enough leisure time. Therefore alliances based on synergies between capitalism and Wikipedia could be necessary during a prolonged transition to potential communism.

Jakob Rigi maintains that the "logic of equivalents" is absent from peer production and does not see any form of on-going classic gift economy in it. He comes to that conclusion from an analysis of the formal rules of some projects and a rather constricted theoretical definition of gift economies (Rigi 2013, 397-398, 400, 403). Instead of a gift economy based on the logic of reciprocity, Rigi sees peer production as a forerunner of communism. Peer production negates alienation by bypassing the division of labour and substituting a "joyful and creative productive activity" for labour. This new way of producing differs from "the common" of Hardt and Negri, which is ubiquitously present in society (Hardt and Negri 2009). Peer production appears as islands within capitalist social formation, and its generalisation will 
require a social revolution (Rigi 2013,4). But before that, the mode of production does not exclude commercial activities from attaching themselves to (mostly) the margins of the projects in the form of services and material products derived from them (Gye 2007a; Bauwens 2009). While these lines of reasoning are somewhat vulnerable to the aforementioned "ideology of digitalism" (Pasquinelli 2008, 72-90), they also reveal pathways for a real emancipatory potential.

Carlo Vercellone $(2007 ; 2010)$ has stressed the increasing importance of rent-based profits in today's capitalism. If that holds true, the exploitation due to user activities on commercial and digital platforms, as well as the increasing importance of the peer production of use values within capitalism, intensifies on a systemic level and in other sectors and parts of the capitalist world system (Caffentzis 2013). This calls for the key importance of connecting the privileged peer production with social movements in the global South.

Moreover, peer production is no more confined to the immaterial or intangible part of the economy, as it has spread to sectors of citizen journalism, open data and open design. Discussions about how to migrate the peer production model to tangibly material production have picked up steam with the development of 3D printers and Fab Labs (Siefkes 2012; Anderson 2012; Maxigas 2012). Crowdfunding and alternative currencies have become important in this context, with their own strengths and weaknesses. For example, Tiziana Terranova and Andrea Fumagalli (2015) have recently examined a crypto currency, Commoncoin, which would be developed into a kind of "money of the common". They maintain that the capability of finance to express the value of such cooperation through a form of money which is not simply exchangeable into commodities but which has the power to shape the future(s) is a crucial stake in new forms of struggle (Ibid 151-152).

For Wikipedia, crowdfunding would probably be a more attainable route towards the "commonification" of the material conditions of immaterial knowledge production. Inge Ejbye Sørensen points out Kickstarter as a pioneer in this field around 2009, but Wikipedia had already been gathering donations for some time by then. He concludes that there are 95 different crowdfunding sites in the UK today that are supporting various projects and start-ups (Ejbye Sørensen 2015, 269). Crowdfunding has different faces: it could refer to donations, rewards, pledging, peer lending, patronage, or be based on royalties or equities (Ejbye Sørensen 2015, 269; Ridgway 2015, 283-287). Ejbye Sørensen stresses the importance of monitoring the working conditions in these projects as well as how the quality of production complies with professional standards (Ejbye Sørensen 2015, 279; cf. Duguid 2006). In contrast, Renée Ridgway contends that crowdfunding can go in different political directions. In a neoliberal version, it can lead to cuts from in the public expenditure-Kickstarter contributed more with its micro-donations to the relevant fields in 2013 than National Endowments of the Arts in USA. The Spanish project Goteo points in another direction. It is a social network for collective financing built on monetary and non-monetary contributions. The project is focused on building support for the commons (Ridgway 2015, 282-283). Wikipedia, then, has to address these socio-economic and political questions so that it contributes on an overall level to the strengthening of the commons instead of neoliberal state reforms and deepening exploitation.

These examples of a latent stream of capitalism of communism (which is slowly outcompeting rather than using the class struggle against capitalism) portray a principally emancipatory force that has some serious obstacles ahead of it, but it can be made more sustainable through the inclusion of a anti-capitalist critique of the ideological formations that Lund (2015a) identifies in the Swedish Wikipedia.

Different and conflicting ideologies exist in the Swedish project regarding wage labour within the editing process in the hands of Wikimedia Foundation, as well as financed by external actors. Paradoxically, on the surface of things, wage labour in the hands of the nonprofit foundation is perceived as more dangerous for the project if applied within editing, than if the paid editing is externally financed in the form of Wikipedians in Residence within external actors. External commercial actors are not seen as dangerously powerful when it comes to the actual activity of peer production. And feelings of injustice are not being triggered when the wages come from somewhere else (Lund 2015a; 2015b). 
On an ideological level the Wikipedians, according to Lund's study, seem to be in favour of wage labour within Wikipedia, but to various degrees and often with qualifications. The contributors stress the need for wage labour when it comes to certain tasks outside of the editing process. Some of them have a narrower view about this "commercial outside" to peer production than others. The non-commerciality of the WMF is sometimes expressed as a reason for this acceptance. An identified ideological formation named the peripheral within the Swedish Wikipedian community is sceptical to wage labour in the hands of the foundation in the editing. This formation is rather informal and playful in character. Another identified ideological formation, the bottom-up formation, shares this view, but they are more in favour of the ongoing professional focus within Wikipedia on improving the quality of the encyclopaedia according to abstract standards than the peripheral formation is. This ideological formation explicitly positions itself against wage labour in the hands of WMF within the editing process as something that risks impairing peer production. On the other hand, there is also an ideological top-down formation. This formation does not see any problems with the foundation using their wage labour in the editing process. According to them, there is no consensus against this practice, and there is not even a problem, because it will not happen as it is not effectively used money for the foundation (Lund 2015a; 2015b).

The three identified ideological formations, the peripheral, bottom-up and top-down, show that the support for some wage labour within the project is not unqualified. Two out of three formations want to keep wages paid by the foundation outside of editing. These ideological formations are the ones that need to be supported in a way that helps Wikipedia to enter into empowering alliances with capitalist companies as well as other institutions.

A business-friendly standpoint has to be checked and counteracted by a revitalized theory that critically examines the peer production projects' alliances with capital. Not all alliances with the other mode of production (capitalism) benefit Wikipedia or other voluntary projects. Such a critical perspective is urgently needed: on a macro level Lund's study concludes that the Swedish Wikipedia is dominated by ideological formations that stress the non-friction or non-importance of the friction between peer production and capitalism (Lund 2015a), and the future will hopefully see some attempts at formulating a critique against these formations

\section{Conclusions}

This article has elaborated on the materialities of commons-based peer production by examining the lines of conflict occurring around the economic relations of Wikipedia, and particularly with regard to its relation to increasing commercial pressures.

We began by stating our view that an understanding of the social collaboration upon the digital commons as "immaterial"' is one of the persistent problems in the commons debate, and that this conception should be deconstructed and replaced by a more detailed analysis of the different material layers required to sustain the production. But similarly, any understanding of immaterial commoning solely through the looking glass of its environmental impacts would be an underestimation of its potentials. We proposed that the analysis of monetary materialities should include the inputs that are required to sustain the operations of the commons system, but also, by extension, the ones that sustain the lives of the commoners themselves. In this context, we sought to problematize and cross-examine the issues of paid editing and paid advocacy by analysing the debates within the community after the revealing of the Wiki-PR scandal in 2013. In our analysis, we focused on the revision of the Terms of Use for all of the Wikimedia Foundation's projects, a measure that took place after the three community-led policy proposals to regulate paid advocacy had failed due to the lack of any consensus.

In comparison to other notable examples of peer production (such as GNU/Linux), we concluded that Wikipedia is marked by its strong aversion towards money and its endorsement of the use of unpaid work to produce the desired end product, the common encyclopaedia of knowledge. At the same time, Wikipedia is technologically dependent on assets that cannot be acquired or maintained without money. These assets include the technical equipment, such as the data centres, but also and most importantly the unpaid contributions 
from the voluntary editors. The editing community is understood as the actual core of Wikipedia, whereas Wikimedia Foundation is seen as a backdrop, technological provider and media representative, working behind the scenes of the actual processes of peer production. However, most of the money-related activities are also managed within the foundation, which increases its institutional power within and in relation to the volunteering community. Wikipedia's hybrid economy - with the centralized monetary technological assets, on the one hand, and the decentralized, commons-based knowledge production, on the other hand-is prone to political tensions, which however are foregrounded only in exceptional circumstances.

The Wiki-PR affair and its resonances teach us an important lesson about how Wikipedia (as a community of commoners) and Wikimedia Foundation handle the materialities of their projects. First of all, there seems to exist, as Osman (2014) rightly points out, a notable share of Wikipedians in favour of paid editing within the scheme of commons-based peer production. The problem with Osman's analysis is that he regards this as a new situation, implying that Wikipedia was less commercially dependent before. In our understanding, this is not the case: there has never been an era of a paradise, but rather a continuous process of selftransformation.

As Sue Gardner, executive director of the Wikimedia Foundation from 2007 to 2014, admits in her press statement (2013), the discussion on paid editing has been "a divisive topic inside Wikipedia for many years". Wikipedia was initially established and owned by a private company Bomis, but later was passed on to a non-commercial foundation. This foundation has now, due to the Wiki-PR affair, sharpened the terms of use so that for the time being, paid editing is condemned whenever it takes a hidden and unregulated form, while paid advocacy is always plain wrong and against guidelines and policies. The solution leaves some flexibility for special circumstances and alternative policies in specific projects if the concerned community wants to pursue them.

In the debates in Wikipedia's community journal, The Signpost, the German Wikipedia is mentioned as an example to follow. Wikipedia should take the "bull by the horns, as the German WP has done", user Tony states. "I believe de.WP has about 500 such accounts, and they are watched wherever they go. It's not ideal, but it's more practical than what we have now". Tony gets the support of user 3/4-10 who concludes: "I believe that's where the future ought to lie for all WPs, regarding this topic", and user Chris.urs-0: "I agree. Good faith editing should be separated from propaganda lies" (The ed17 and Jayen466 2013). It could be argued that the amendment of the Terms of Use that was crafted shortly thereafter was a first step in this process.

The role of Wikipedia's founding figure, Jimmy Wales, in the debates is interesting. The actions of the foundation in sharpening the terms of use to defend the reliability and independence of the project are rather moderate in expression, whereas Wales talks of a "bright line" that should not be crossed when it comes to paid editing. This standpoint is annoying to some Wikipedians. User Tony states: "I'm uncomfortable with Jimbo's anti-paid-editing line: it's just unrealistic, even though l'd sooner have zero tolerance for PE [paid editing] on foundation sites if we could identify PE" (Gnom et al. 2012).

Wales behaves, in our view, as a kind of defensive libero in a rather iconoclastic and elevated way. He is and should be pure so that the project does not lose its voluntary and noncommercial character. The foundation, however, takes a middle position that is more practical but still more principled than those of many Wikipedians, especially in small-language versions, that are engaged in practical editing. These commoners are the ones that could face problems in finding a way to reproduce themselves as Wikipedians in a capitalist world, and therefore maybe it is not so surprising that they are more in favour of paid editing than Wales and the foundation, even if there are conflicting views on this in the community. The debate between these Wikipedians and user Coretheapple who calls them a "paid editing fan club" is rather an example of a heightened political discussion within the project than a declining one, as Osman seems to portray it.

All in all, we are witnessing increasing attempts to contain and control the commercial influence on Wikipedia and to direct business activities to the advantage of the project. This is not a sign of a less radical community within the peer production, but rather an example of a 
capitalism of the commons (Bauwens and Kostakis 2014, 356-361), or as we put it, a capitalism of communism.

For this ideological current to survive and prosper it should be informed by more critical perspectives against paid editing, wage labour in general, and continuously increased fundraising. Dimitry Kleiner's (2010) concept of venture communes could be an inspiration for discussions of reforms of the foundations and its local chapters' character, in more decentralized ways. Also, Bauwens' elaboration (2012) on Kleiner's Peer Production License (2010) could show the way if the project's alliances with capital and companies become problematic.

For now, it seems more progressive to make these alliances in the current manner under a copyleft license, but this could change quickly. From academia, especially critical theory has the responsibility to help these germs of a new mode of production to grow stronger while still pointing outside the confines of capitalism.

\section{References}

Anderson, Chris. 2012. Makers: The New Industrial Revolution. 1st edn. London: Random House Business Books.

Band, Jonathan, and Jonathan Gerafi. 2013. "Wikipedia's Economic Value." SSRN Scholarly Paper ID 2338563. Rochester, NY: Social Science Research Network. http://papers.ssrn.com/abstract=2338563.

Bauwens, Michel. 2009. Class and Capital in Peer Production. Class \& Capital 33 (1): 121-141.

Bauwens, Michael. 2012. From the Theory of Peer Production to the Production of Peer Production Theory. Journal of Peer Production, no. 1. http://peerproduction.net/issues/issue-1/invitedcomments/from-the-theory-of-peer-production-to-the-production-of-peer-production-theory/.

Bauwens, Michel, and Franco lacomella. 2012. Peer-to-Peer Economy and New Civilization Centered Around the Sustenance of the Commons. In The Wealth of the Commons. A World Beyond Market and State. Massachusetts: Levellers Press. http://wealthofthecommons.org/essay/peer-peereconomy-and-new-civilization-centered-around-sustenance-commons.

Bauwens, Michel, and Vasilis Kostakis. 2014. From the Communism of Capital to Capital for the Commons: Towards an Open Co-Operativism. tripleC: Communication, Capitalism \& Critique. Open Access Journal for a Global Sustainable Information Society 12 (1): 356-361.

Benkler, Yochai. 2002. Coase's Penguin, Or, Linux and The Nature of the Firm. Yale Law Journal, 369-446. Accessed May 26, 2015.

Benkler, Yochai. 2006. The Wealth of Networks: How Social Production Transforms Markets and Freedom. New Haven [Conn.]: Yale University Press.

Benkler, Yochai. 2011. The Penguin and the Leviathan: The Triumph of Cooperation over SelfInterest. New York: Crown Business.

Benkler, Yochai, and Helen Nissenbaum. 2006. Commons-Based Peer Production and Virtue*. Journal of Political Philosophy 14 (4): 394-419.

Beverungen, Armin, Anna-Maria Murtola, and Gregory Schwartz. 2013. "The Communism of Capital?" Ephemera: Theory \& Politics in Organization 13 (3): 483-495.

Boyle, James. 1996. Shamans, Software, and Spleens: Law and the Construction of the Information Society. Cambridge, Mass.: Harvard University Press.

Brake, David R. 2014. Are We All Online Content Creators Now? Web 2.0 and Digital Divides. Journal of Computer-Mediated Communication 19 (3): 591-609. doi:10.1111/jcc4.12042.

Bruns, Axel. 2011. "Beyond Difference: Reconfiguring Education for the User-Led Age." In Digital Difference: Perspectives on Online Learning, edited by Ray Land and Siân Bayne, 133-144. Rotterdam: Sense.

Caffentzis, George. 2013. In Letters of Blood and Fire: Work, Machines, and the Crisis of Capitalism. Oakland, Calif: PM Press.

Caffentzis, George, and Silvia Federici. 2014. Commons against and beyond Capitalism. Community Development Journal 49 (suppl 1): i92-i105. doi:10.1093/cdj/bsu006.

Corsani, Antonella, Maurizio Lazzarato, and Antonio Negri. 1996. Le bassin de travail immateriel (BTI) dans la metropole parisienne. Paris: L'harmattan.

Dardot, Pierre, and Christian Laval. 2014. Commun. Paris: La Découverte.

Davey, Brian. 2010. Abundance of Food vs the Abundance of Recipes. Accessed June 3, 2015. http://p2pfoundation.net/Abundance_of_Food_vs_the_Abundance_of_Recipes. 
De Angelis, Massimo. 2012. Crises, Capital and Co-Optation: Does Capital Need a Commons Fix? In The Wealth of the Commons. A World Beyond Market and State, edited by David Bollier and Silke Helfrich. Massachusetts: Levellers Press. http://wealthofthecommons.org/essay/crises-capital-andco-optation-does-capital-need-commons-fix.

DeLanda, Manuel. 2002. Intensive Science and Virtual Philosophy. London; New York: Continuum.

DeLanda, Manuel. 2006. A New Philosophy of Society: Assemblage Theory and Social Complexity. London: Continuum.

Duguid, Paul. 2006. Limits of Self-Organization: Peer Production and 'Laws of Quality'. First Monday 11 (10). http://firstmonday.org/ojs/index.php/fm/article/view/1405.

Ejbye Sørensen, Inge. 2015. Go Crowdfund Yourself! Some Unintended Consequences of Crowdfunding for Documentary Film and Industry in the U.K. In MoneyLab Reader: An Intervention in Digital Economy, edited by Geert Lovink, Nathaniel Tkacz, and Patricia de Vries, 268-280. INC Reader 10. Amsterdam: Institute for Network Cultures.

Federici, Silvia. 2012. Revolution at Point Zero: Housework, Reproduction, and Feminist Struggle. 1 edition. Oakland, CA : Brooklyn, NY: London: PM Press.

Federici, Silvia, and George Caffentzis. 2013. Commons Against and Beyond Capitalism - Upping the Anti. Upping the Anti: A Journal of Theory and Action 15: 83-97. Accessed September 7, 2015.

Firer-Blaess, Sylvain, and Christian Fuchs. 2014. "Wikipedia: An Info-Communist Manifesto." Television and New Media 15 (2): 87-103. doi:10.1177/1527476412450193.

Geiger, R. Stuart, and Aaron Halfaker. 2013. Using Edit Sessions to Measure Participation in Wikipedia. In Proceedings of the 2013 Conference on Computer Supported Cooperative Work, 861-870. ACM. http://dl.acm.org/citation.cfm?id=2441873.

Glott, Ruediger, Philipp Schmidt, and Rishab Ghosh. 2009. Wikipedia Survey_First Results. Working Draft. Accessed May 23, 2015.

http://upload.wikimedia.org/wikipedia/foundation/a/a7/Wikipedia_General_SurveyOverview_0.3.9.pdf.

Gnom, Sandstein, Jan eissfeldt, and Tony1. 2012. "Court Ruling Complicates the Paid-Editing Debate." The Signpost. December 11. Accessed June 14, 2015. https://en.wikipedia.org/w/index.php?title=Wikipedia:Wikipedia_Signpost/2012-11$12 /$ News and notes\&oldid $=535001276$.

Go Phightins! 2013. Wikipedia:Wikipedia Signpost/2013-05-13/In the Media. The Signpost. May 13. Accessed June 14, 2015. https://en.wikipedia.org/w/index.php?title=Wikipedia:Wikipedia_Signpost/2013-0513/In the media\&oldid $=660395296$.

Go Phightins!, Jayen466, and Andrewman327. 2013. The Decline of Wikipedia; Sue Gardner Releases Statement on Wiki-PR; Australian Minister Relies on Wikipedia. The Signpost. October 23. Accessed June 14, 2015. https://en.wikipedia.org/w/index.php?title=Wikipedia:Wikipedia_Signpost/2013-1023/In the media\&oldid $=596414279$.

Google. 2012. December 31, 2011 Annual Report. Accessed June 14, 2012. http://investor.google.com/pdf/2011_google_annual_report.pdf.

Guldbrandsson, Lennart. 2008. Så fungerar Wikipedia : allt du behöver veta om hur man bidrar, om kritiken och om kvalitetssatsningarna. 1st edn. Ronneby: Hexa Förlag.

Gye, Lisa. 2007a. Michel Bauwens Part 1. Accessed May 23, 2015. https://www.youtube.com/watch?v=Dn929K_jVQI.

Gye, Lisa. 2007b. Michel Bauwens Part 2. Accessed May 23, 2015. https://www.youtube.com/watch?v=-J3G6sbvaac.

Hardin, Garrett. 1968. The Tragedy of the Commons. Science 162 (3859): 1243-1248. doi:10.1126/science.162.3859.1243.

Hardt, Michael, and Antonio Negri. 2009. Commonwealth. Cambridge, Mass.: Belknap Press of Harvard University Press.

Juhel, Vincent. 2011. Valorisation du bénévolat sur Wikipédia. Paris: HEC. http://www.amplyd.com/these/Valorisation du bénévolat sur Wikipédia - FEB2012 - Vincent Juhel.pdf.

Kaplan, Andreas M., and Michael Haenlein. 2010. Users of the World, Unite! The Challenges and Opportunities of Social Media. Business Horizons 53 (1): 59-68. doi:10.1016/j.bushor.2009.09.003.

Karatzogianni, Athina, and George Michaelides. 2009. Cyberconflict at the Edge of Chaos: Cryptohierarchies and Self-Organisation in the Open-Source Movement. Capital \& Class 33 (1): 143-157. doi:10.1177/030981680909700108. 
Kleiner, Dmytri. 2010. The Telekommunist Manifesto. Amsterdam: Institute of Network Cultures.

Kohtala, Cindy. 2014. Addressing Sustainability in Research on Distributed Production: An Integrated Literature Review. Journal of Cleaner Production. Accessed June 3, 2015. doi:10.1016/j.jclepro.2014.09.039.

Kohtala, Cindy, and Sampsa Hyysalo. 2015. Anticipated Environmental Sustainability of Personal Fabrication. Journal of Cleaner Production 99: 333-344. Accessed June 3, 2015. doi:10.1016/j.jclepro.2015.02.093.

Kostakis, Vasilis. 2013. At the Turning Point of the Current Techno-Economic Paradigm: CommonsBased Peer Production, Desktop Manufacturing and the Role of Civil Society in the Perezian Framework. tripleC: Communication, Capitalism \& Critique. Open Access Journal for a Global Sustainable Information Society 11 (1): 173-190.

Kostakis, Vasilis, Vasilis Niaros, and Christos Giotitsas. 2014. Production and Governance in Hackerspaces: A Manifestation of Commons-Based Peer Production in the Physical Realm? International Journal of Cultural Studies, February, 1367877913519310. Accessed June 3, 2015. doi:10.1177/1367877913519310.

Kostakis, Vasilis, and Marios Papachristou. 2014. Commons-Based Peer Production and Digital Fabrication: The Case of a RepRap-Based, Lego-Built 3D Printing-Milling Machine. Telematics and Informatics 31 (3): 434-443. doi:10.1016/j.tele.2013.09.006.

Langlois, Ganaele, and Greg Elmer. 2009. Wikipedia Leeches? The Promotion of Traffic through a Collaborative Web Format. New Media \& Society 11 (5): 773-794. doi:10.1177/1461444809105351.

Leonardi, Paul M. 2012. Materiality, Sociomateriality, and Socio-Technical Systems: What Do These Terms Mean? How Are They Related? Do We Need Them? Materiality and Organizing: Social Interaction in a Technological World, 25-48. Accessed June 11, 2015.

Lessig, Lawrence. 2001. The Future of Ideas: The Fate of the Commons in a Connected World. 1st ed. New York: Random House.

Lih, Andrew. 2009. The Wikipedia Revolution: How a Bunch of Nobodies Created the World's Greatest Encyclopedia. New York: Hyperion.

Linebaugh, Peter. 2008. The Magna Carta Manifesto. Liberties and Commons for All. Berkeley: University of California Press.

Litman, Jessica. 2001. Digital Copyright: Protecting Intellectual Property on the Internet. New York: Prometheus Books.

Lovink, Geert. 2009. Society of the Query. The Googlization of Our Lives. In Deep Search: The Politics of Search beyond Google, edited by Konrad Becker and Felix Stalder, 45-53. Innsbruck and Piscataway, N.J.: Studien Verlag.

Lund, Arwid. 2015a. Frihetens rike: wikipedianer om sin praktik, sitt produktionssätt och kapitalismen. Hägersten: Tankekraft förlag.

Lund, Arwid. 2015b. Wikipedians on Wage Labour within Peer Production. In Digital Labour and Prosumer Capitalism: The US Matrix, edited by Matthew O'Neill and Olivier Frayssé. Palgrave Macmillan. http://www.diva-portal.org/smash/record.jsf?pid=diva2\%3A768405\&dswid=8485.

Mattei, Ugo. 2011. Beni comuni. Un manifesto. Paris: Gius. Laterza \& Figli.

Marx, Karl, and Friedrich Engels. 1998. The German Ideology, Including Theses on Feuerbach. Paperback edition. Amherst, N.Y: Prometheus Books.

Maxigas. 2012. Hacklabs and Hackerspaces-Tracing Two Genealogies. Journal of Peer Production, no. 2. http://peerproduction.net/issues/issue-2/peer-reviewed-papers/hacklabs-and-hackerspaces/.

Merten, Stefan, and Stefan Meretz. 2015. Germ Form Theory: Peer Production in a Historical Perspective. Accessed May 23, 2015. http://www.oekonux.org/texts/GermFormTheory.html.

Merton, Robert King. 1973. The Sociology of Science: Theoretical and Empirical Investigations. Chicago: University of Chicago Press.

Meta-Wiki contributors. 2015a. Fundraising/2013-14 Report - Meta. Meta-Wiki. October 8. Accessed September 3, 2015. https://meta.wikimedia.org/w/index.php?title=Fundraising/201314 Report\&oldid=13069745.

Meta-Wiki contributors. 2015b. "Wikimedia Servers." Meta-Wiki. April 23. Accessed May 26, 2015. http://meta. wikimedia.org/w/index.php?title=Wikimedia_servers\&oldid=12004447.

Moore, Phoebe. 2011. Subjectivity in the Ecologies of P2P Production. The Fibreculture Journal, no. 17. http://seventeen.fibreculturejournal.org/fcj-119-peer-to-peer-production-a-revolutionary-orneoliberal-mode-of-subjectivation/.

Moulier Boutang, Yann. 2011. Cognitive Capitalism. Cambridge: Polity Press. 
Ortega, Felipe. 2009. Wikipedia: A Quantitative Analysis. Madrid: Universidad Rey Juan Carlos. http://www.researchgate.net/publication/200773248_Wikipedia_A quantitative_analysis.

Osman, Kim. 2014. The Free Encyclopaedia That Anyone Can Edit: The Shifting Values of Wikipedia Editors. Culture Unbound: Journal of Current Cultural Research 6 (3): 593-607. doi:10.3384/cu.2000.1525.146593.

Owens, Simon. 2013. The Battle to Destroy Wikipedia's Biggest Sockpuppet Army. The Daily Dot. August 10. Accessed June 14, 2015. http://www.dailydot.com/lifestyle/wikipedia-sockpuppetinvestigation-largest-network-history-wiki-pr/.

Pasquinelli, Matteo. 2008. Animal Spirits: A Bestiary of the Commons. Rotterdam: NAi Publishers / Institute of Network Cultures.

Paumier, Guillaume. 2013. Wikimedia Sites to Move to Primary Data Center in Ashburn, Virginia. Wikimedia Blog. January 19. Accessed May 26, 2015. http://blog.wikimedia.org/2013/01/19/wikimedia-sites-move-to-primary-data-center-in-ashburnvirginia/.

Pouwelse, Johan A., Pawel Garbacki, Dick Epema, and Henk Sips. 2008. Pirates and Samaritans: A Decade of Measurements on Peer Production and Their Implications for Net Neutrality and Copyright. Telecommunications Policy 32: 701-712.

Rebello, Justin. 2009. Marketing Your Firm with Wikipedia. Rhode Island Lawyers Weekly. August 12. Accessed May 24, 2015. http://rilawyersweekly.com/blog/2009/08/12/marketing-your-firm-withwikipedia/.

Ridgway, Renée. 2015. Crowdfunding the Commons? In MoneyLab Reader: An Intervention in Digital Economy, edited by Geert Lovink, Nathaniel Tkacz, and Patricia de Vries, 281-294. INC Reader 10. Amsterdam: Institute for Network Cultures.

Rifkin, Jeremy. 2014. The Zero Marginal Cost Society: The Internet of Things, the Collaborative Commons, and the Eclipse of Capitalism. New York: Palgrave Macmillan.

Rigi, Jakob. 2013a. Peer Production and Marxian Communism: Contours of a New Emerging Mode of Production. Capital \& Class 37 (3): 397-416. doi:10.1177/0309816813503979.

Rigi, Jakob. 2013b. Peer Production and Marxian Communism: Contours of a New Emerging Mode of Production. Capital \& Class 37 (3): 397-416. doi:10.1177/0309816813503979.

Rose, Carol. 1986. The Comedy of the Commons: Commerce, Custom, and Inherently Public Property. 1828. Faculty Scholarship Series. New Haven, CT: Yale Law School. http://digitalcommons.law.yale.edu/fss papers/1828.

Shantz, Jeff. 2013. Commonist Tendencies: Mutual Aid Beyond Communism. Brooklyn, NY: punctum books.

Siefkes, Christian. 2008. From Exchange to Contributions Generalizing Peer Production into the Physical World. Berlin: Ed. Siefkes. http://libros.metabiblioteca.org/handle/001/285.

Siefkes, Christian. 2012. Beyond Digital Plenty: Building Blocks for Physical Peer Production. Journal of Peer Production 1. http://peerproduction.net/issues/issue-1/invited-comments/beyond-digitalplenty/.

Starosta, Guido. 2012. Cognitive Commodities and the Value-Form. Science \& Society 76 (3): $365-$ 392. doi:10.1521/siso.2012.76.3.365.

Terranova, Tiziana, and Andrea Fumagalli. 2015. Financial Capital and the Money of the Common: The Case of Commoncoin. In MoneyLab Reader: An Intervention in Digital Economy, edited by Geert Lovink, Nathaniel Tkacz, and Patricia de Vries, 150-157. INC Reader 10. Amsterdam: Institute for Network Cultures.

The ed17. 2014a. Foundation Takes Aim at Undisclosed Paid Editing; Greek Wikipedia Editor Faces down Legal Challenge. The Signpost. February 19. Accessed June 14, 2015. https://en.wikipedia.org/w/index.php?title=Wikipedia:Wikipedia_Signpost/2014-02$19 /$ News and notes\&oldid $=628269948$.

The ed17. 2014b. With Paid Advocacy in Its Sights, the Wikimedia Foundation Amends Their Terms of Use. The Signpost. June 18. Accessed June 14, 2015.

https://en.wikipedia.org/w/index.php?title=Wikipedia:Wikipedia_Signpost/2014-0618/News_and notes\&oldid=617798682.

The ed17, and Jayen466. 2013. Vice on Wiki-PR's Paid Advocacy; Featured List Elections Begin. The Signpost. October 16. Accessed June 14, 2015.

https://en.wikipedia.org/w/index.php?title=Wikipedia:Wikipedia_Signpost/2013-10$16 /$ News and notes\&oldid=593634503.

The ed17, and Tony1. 2013. Foundation to Wiki-PR: Cease and Desist; Arbitration Committee Elections Starting. The Signpost. November 20. Accessed June 14, 2015. 
https://en.wikipedia.org/w/index.php?title=Wikipedia:Wikipedia_Signpost/2013-1120/News and notes\&oldid=593647620.

Troxler, Peter. 2010. Commons-Based Peer-Production of Physical Goods: Is There Room for a Hybrid Innovation Ecology? SSRN Scholarly Paper ID 1692617. Rochester, NY: Social Science Research Network. http://papers.ssrn.com/abstract=1692617.

Vercellone, Carlo. 2007. From Formal Subsumption to General Intellect: Elements for a Marxist Reading of the Thesis of Cognitive Capitalism. Historical Materialism 15 (1): 13-36.

Vercellone, Carlo. 2010. The Crisis of the Law of Value and the Becoming-Rent of Profit. In Crisis in the Global Economy: Financial Markets, Social Struggles, and New Political Scenarios, edited by Andrea Fumagalli and Sandro Mezzadra, 85-118. Los Angeles: Semiotext(e).

Verge, Jason. 2013. It's Official: Ashburn Is Wikipedia's New Home. Data Center Knowledge. January 14. Accessed May 26, 2015. http://www.datacenterknowledge.com/archives/2013/01/14/its-officialequinix-ashburn-is-wikimedias-home/.

Virno, Paolo. 2004. A Grammar of the Multitude: For an Analysis of Contemporary Forms of Life. Los Angeles, CA; Cambridge, Mass.: Semiotext (e) ; Distributed by MIT Press. http://search.ebscohost.com/login.aspx?direct=trueandscope=siteanddb=nlebkanddb=nlabkandAN $=138668$.

Wikimedia Foundation. n.d. Wikimedia Foundation 2013-2014 Annual Report. Accessed June 14, 2015. https://annual.wikimedia.org/2014/.

Wikimedia Foundation. 2011. Wikipedia Editors Study. Results from the Editor Survey, April 2011. Accessed May 24, 2015.

https://upload.wikimedia.org/wikipedia/commons/7/76/Editor_Survey_Report_-_April_2011.pdf.

Wikimedia Foundation. 2015. Our Projects-Wikimedia Foundation. March 22. Accessed June 11, 2015. https://wikimediafoundation.org/w/index.php?title=Our projects\&oldid=101350.

Wikimedia Stats. 2015a. Page Views for Wikipedia, All Platforms, Normalized. Accessed May 26, 2015. http://stats.wikimedia.org/EN/TablesPageViewsMonthlyCombined.htm.

Wikimedia Stats. 2015b. Wikimedia Report Card June 2015. Accessed May 26, 2015. http://reportcard.wmflabs.org/.

Wikipedia contributors. 2012. Wikipedia talk:No Paid Advocacy. Wikipedia, the Free Encyclopedia. Accessed June 14, 2015. https://en.wikipedia.org/w/index.php?title=Wikipedia_talk:No_paid_advocacy\&oldid=519700067.

Wikipedia contributors. 2015. List of Wikipedias. Wikipedia, the Free Encyclopedia. Accessed June 11, 2015. http://en. wikipedia.org/w/index.php?title=List of Wikipedias\&oldid=666467686.

WWDC. 2011. WWDC 2011 Liveblog: Steve Jobs Talks iOS 5, OS X Lion, iCloud and More! June 6. Accessed May 25, 2015. http://www.engadget.com/2011/06/06/wwdc-2011-liveblog-steve-jobstalks-ios-5-os-x-lion-icloud-an/. 


\section{About the Authors}

\section{Arwid Lund}

$\mathrm{PhD}$ in Information Studies, researcher in Library and Information Science at the Department of ALM (Archival Studies, Library and Information Science, Museum and Cultural Heritage Studies), Uppsala University, Sweden, who publicly defended his dissertation (Realm of Freedom, Wikipedians on their practice, mode of production and capitalism) on October 2, 2015. He is the author of three books in Swedish, and has worked as a librarian with digital publishing and digital repositories. He was an activist in social movements during the 1990's, and the first years of the new millennium. You can contact Arwid Lund at arwid.lund@abm.uu.se.

\section{Juhana Venäläinen}

$\mathrm{PhD}$, researcher in Cultural Studies at the University of Eastern Finland, Joensuu. His research projects revolve around interlinks, tensions and collisions between the spheres of culture and the economy, with recent contributions focusing on the strategic roles of the commons in creating economic value in contemporary capitalism. Guided by this theoretical perspective, he has explored a variety of topic areas, from squatting to soundscape tourism, fashion theory and beyond. Visit: www.juhanavenalainen.net. 